\title{
Premature Mortality Costs Associated with Lifestyle Factors among US Citizens
}

Gavin Putzer* and Juan Jaramillo

UCF COM, Burnett College of Biomedical Sciences, Orlando, USA

\begin{abstract}
Purpose: The leading causes of mortality in the US include chronic diseases such as heart disease, stroke, and cancer These diseases may also be classified as major "lifestyle" diseases that trace partially to imprudent living and risky behavior.

Design: To examine the monetary costs of lifestyle choices.

Setting: USA

Subjects: USA citizens

Measures: We utilized the most recent data from the National Center for Health Statistics and mortality costs from the USA Census Bureau in order to estimate the costs of lifestyle decisions leading to premature death.

Analysis: This study examines the monetary costs associated with six personal lifestyle decisions-smoking, diet, excessive alcohol consumption, illicit drug use, accidents, sexually transmitted infections-and consequent premature mortalities.

Results: Our study showed that $40.0 \%$ of the 2.47 million deaths annually in the USA may be attributed to lifestyle decisions. The majority of premature deaths that occurred were associated with three lifestyle decisions-smoking, obesity or excessive alcohol consumption. Smoking, obesity, sexually transmitted infections and accidents decreased vis-à-vis the previous decade; whereas, illicit drugs and alcohol-related premature deaths increased from the previous decade.

Conclusion: The value of lifetime earnings lost among individuals as a consequence of lifestyle choices is $\$ 241$ billion annually. The prospect for future declines in these premature deaths will most likely depend on a decrease in risk factors, continued lifestyle modification and population-based intervention strategies.
\end{abstract}

Keywords: Health management; Lifestyle factors; Premature deaths; Financial costs; Chronic diseases; Health policy

\section{Introduction}

The health status of populations has long been a focus for policymakers. Seminal work in the United States (US) established the contributions that factors such as environment and lifestyle make to population health $[1,2,3]$. Early studies examining population health showed limited correlation between health expenditures and population health, until Wolfe [4] controlled for lifestyle, revealing a positive correlation between them. The leading causes of mortality in the USA include heart disease, cancer, stroke and diabetes. These diseases have genetic components, but are also the major "lifestyle" diseases that trace tangibly to imprudent living and risky behavior.

Keeney [5] examined how personal decision making affects mortality rates. He found one million of the 2.4 million deaths in 2000 were attributed to personal decisions and could have been avoided if readily available alternative choices were made. Keeney [5] described a personal decision as a situation where an individual can make a choice between two or more alternatives. His analysis assumed that there were many decisions prior to death and that with respect to at least of one these decisions, the individual did have control of the choice and was aware of an alternative which, if chosen, could have avoided the premature death.

Heart disease, cancer and stroke have been the leading causes of mortality over the past several decades [6,7] Each of these conditions is caused by a number of factors. Two such factors affecting these conditions are smoking [8,9] and being overweight [10]. Smoking is a personal choice made by an individual. Overeating is a personal choice made by an individual, although many studies suggest there is also a genetic link $[11,12]$. Notwithstanding the genetic predispositions affecting health, these lifestyle choices often lead to premature deaths. A premature death may be defined as when an individual dies sooner than he/she would have if a different choice(s) had been made.

There are other lifestyle choices which may lead to premature deaths, such as excessive alcohol consumption, motor vehicle accidents attributable to drunk driving or speeding, physical inactivity, sexually transmitted infections and illicit drug use. Each of these six personal decisions is a focus of this paper because each lifestyle choice involves an individual deciding to engage in such a choice despite the risks to his/her health. This work extends other studies in an important way in that it examines the value of lifetime earnings lost (VLTEL) as a result of lifestyle choices.

\section{Methods}

Our study utilizes 2010 data from the National Center for Health

*Corresponding author: Putzer G, Adjunct Professor of Medicine, UCF COM, Burnett College of Biomedical Sciences, 6900 Lake Nona Blvd., Orlando, Fl 32827, USA, Tel: +4078235932; E-mail: gputzer@mail.ucf.edu

Received August 28, 2015; Accepted December 10, 2015; Published December 14,2015

Citation: Putzer G, Jaramillo J (2015) Premature Mortality Costs Associated with Lifestyle Factors among US Citizens. Review Pub Administration Manag 3: 177. doi:10.4172/2315-7844.1000177

Copyright: $\odot 2015$ Putzer G, et al. This is an open-access article distributed under the terms of the Creative Commons Attribution License, which permits unrestricted use, distribution, and reproduction in any medium, provided the original author and source are credited. 
Statistics [7] and mortality costs from the US Census Bureau [9] to calculate the costs of personal decisions leading to premature death (PDLD) and the VLTEL. We utilized the Keeney [5] study which estimated the factors that lead to premature mortality caused by personal decisions from the total number of deaths in the US updated. Our work used recent data and was further differentiated by age stratification.

In our study, the VLTEL is used to measure the impact of each PDLD. The cost of deaths caused by PDLD was estimated as the difference between the cost of all deaths associated with PDLD and the potential cost of these deaths if each individual would avoid any lifestyle choice leading to PDLD. The costs of death due to PDLD were obtained directly by using the number of deaths due to each PDLD and each respective group's age and death costs. Potential death cost (i.e., cost of death if individuals would have avoided PDLD) were obtained using mortality costs and expected death distributions if individuals had not perished at certain ages because of PDLD. The difference between the cost of death caused by PDLD and the potential death cost represents the earnings lost/monetary loss because of PDLD. The analysis was performed for each of the six lifestyle choices.

\section{Results}

Table 1 classifies the number of deaths associated with each of the six lifestyle choices (PDLD) stratified by age. This information was obtained using data from the National Center for Health Statistics [7] in combination with the methodological approach utilized by Keeney [5]. Smoking (439,089 attributable deaths), obesity $(402,471$ attributable deaths) and alcohol (76,670 attributable deaths) were responsible for more than $93 \%$ of the mortality associated with lifestyle choices. Similarly, these causes are responsible for most of the deaths during the economically productive lifespan (25-64 years of age). In addition, accidents (4,434 attributable deaths) and illicit drugs (3,224 attributable deaths) claim the most lives among young adults.

Table 2 summarizes VLTEL for each lifestyle choice. The second column of the table contains the number of mortalities (PDLD) that could be avoided if different lifestyles choices were made. It should be noted that the total number of deaths for each lifestyle choice are smaller than the values showed in Table 1. This is because even if a lifestyle choice is avoided, there remains a probability of dying from natural causes. These probabilities are based on the National Center for Health Statistics [7] data. For example, regarding the 4,420 illicit drug-related deaths among individuals 45-54 years old, only eight mortalities were expected to occur naturally; thus, the remainder was attributed to drugs. The third column represents the VLTEL. The results demonstrate that smoking has the highest VLTEL cost $(\$ 86.3 \mathrm{~B})$ followed by obesity ( $\$ 77.1 \mathrm{~B})$ and alcohol $(\$ 26.3 \mathrm{~B})$. The final column of Table 2 shows the average VLTEL per each death. The highest average VTEL is associated with illicit drugs $(\$ 0.984 \mathrm{M})$ followed by accidents $(\$ 0.751 \mathrm{M})$ and sexually transmitted infections $(\$ 0.618 \mathrm{M})$. These averages are elevated because most of the mortalities associated with these causes occur at younger ages.

It is important to note that 984,771 deaths were attributable to lifestyle choices and presumably could have been avoided with alternative decisions. The VTEL of these deaths is of $\$ 240,745.5 \mathrm{M}$ with a VTEL average of $0.252 \mathrm{M}$ per death.

\section{Discussion}

The British Health and Lifestyle Survey (1984-1985) and the longitudinal follow-up study (2003) examined the determinants of premature mortality in England. These studies showed that lifestyles contributed strongly to inequality in mortality [13]. However, there have been few previous studies tabulating actual causes of death in the US. In 1990, McGinnis and Foege [14] calculated the main contributors to death. The top five causes were tobacco, dietary/activity patterns, alcohol, microbes, and toxic agents. Mokdad et al., [15] updated these results using 2000 data and found the same causes; the main difference was the significant increase of 100,000 deaths annually attributed to physical inactivity and poor diet. In 2008, Keeney calculated the relationships between personal decisions and premature death using 2000 data.

Our study extends each of these previous studies by examining the monetary costs attributable to PDLD utilizing 2010 data. Our data appears to support much of the Keeney study, but with a few distinctions. One positive distinction was that our study shows a reduction of $3.7 \%$ in overall premature deaths with respect to the six lifestyle choices $(984,771)$ compared to the last decade $(1.023$, 045). Our study also differs regarding a decrease in premature deaths attributable to four lifestyle factors: smoking (9.7\%), obesity $(9.3 \%)$, accidents (2.9\%) and sexually transmitted infections (28.2\%). In contrast, there is a significant increase vis-à-vis the previous decade's data regarding premature deaths attributable to illicit drugs $(61 \%)$ and overconsumption of alcohol (13\%). The increase in illicit drug use is especially noted in the 45-54 age cohort and merits further inquiry in a future study.

\begin{tabular}{|c|c|c|c|c|c|c|c|}
\hline \multirow[t]{2}{*}{ Age } & \multicolumn{6}{|c|}{ Lifestyle Cause of Mortality } & \multirow[t]{2}{*}{ Total Mortalities } \\
\hline & Smoking & Obesity & Ilicit Drugs & Alcohol & $\begin{array}{l}\text { Sexually } \\
\text { Transmitted } \\
\text { Infections }\end{array}$ & Accidents & \\
\hline$<1$ & 755 & - & 8 & 1 & - & 81 & 845 \\
\hline $1-4$ & 45 & - & 19 & - & - & 542 & 606 \\
\hline $5-14$ & 40 & - & 26 & - & - & 769 & 835 \\
\hline $15-24$ & 37 & - & 1,654 & 147 & 17 & 5,380 & 7,235 \\
\hline $25-34$ & 46 & 2,367 & 3,224 & 861 & 948 & 4,434 & 11,880 \\
\hline $35-44$ & 6,576 & 7,726 & 3,387 & 4,324 & 2,449 & 3,885 & 28,347 \\
\hline $45-54$ & 33,090 & 29,428 & 4,420 & 14,051 & 4,571 & 4,869 & 90,429 \\
\hline $55-64$ & 76,488 & 60,378 & 2,060 & 18,176 & 3,552 & 4,253 & 164,907 \\
\hline $65-74$ & 95,377 & 80,463 & 253 & 14,060 & 1,490 & 3,278 & 194,921 \\
\hline $75-84$ & 122,417 & 108,385 & 67 & 13,516 & 868 & 4,559 & 249,812 \\
\hline$>85$ & 104,219 & 113,723 & 42 & 11,534 & 347 & 5,090 & 234,955 \\
\hline Total & 439,089 & 402,471 & 15,160 & 76,670 & 14,242 & 37,139 & 984,771 \\
\hline
\end{tabular}

Table 1: Lifestyle choices (PDLD) among age cohorts. 


\begin{tabular}{|l|c|c|c|}
\hline $\begin{array}{l}\text { Lifestyle choice or } \\
\text { personal decision }\end{array}$ & Mortalities & $\begin{array}{c}\text { VLTEL Total in } \\
\text { millions of dollars }\end{array}$ & $\begin{array}{c}\text { Average } \\
\text { \$VLTEL }\end{array}$ \\
\hline Smoking & $425,256.4$ & $86,278.5$ & 0.202886 \\
\hline Obesity & $388,411.2$ & $77,148.8$ & 0.198627 \\
\hline Illicit Drugs & $15,134.6$ & $14,898.2$ & 0.984380 \\
\hline Alcohol & $75,052.0$ & $26,251.9$ & 0.349783 \\
\hline STD & $14,150.8$ & $8,751.2$ & 0.618426 \\
\hline Accidents & $36,505.7$ & $27,416.9$ & 0.751031 \\
\hline TOTAL & $\mathbf{9 5 4 , 5 1 0 . 7}$ & $\mathbf{2 4 0 , 7 4 5 . 5}$ & $\mathbf{0 . 2 5 2 2 2 2}$ \\
\hline
\end{tabular}

VLTEL - Value of lifetime earnings forgone or lost due to premature mortality

Table 2: Average VLTEL* (\$Millions) per lifestyle choice.

In 2009-2011, the US spent on average \$2.6 trillion on healthcare annually; representing $\sim 18 \%$ of gross domestic product [16]. There were 2.47 million deaths in the US in 2010 [9] and $40 \%$ may be classified as premature deaths partially attributed to lifestyle decisions. Each of the six lifestyle choices examined in our study resulted in large numbers of premature deaths whereby there were alternative choices that presumably could have avoided these premature deaths. For example, an individual's decision to smoke cigarettes significantly influences the risk of various cancers (e.g., lung, kidney) and/or cardiovascular diseases. Or, an individual's dietary habits (e.g., cholesterol intake), alcohol consumption and the amount of exercise significantly influence being overweight, which influences, a higher risk of cardiovascular disease and cancer. According to a recent study, individuals who smoke, do not exercise, eat poorly, and drink alcohol are three times more likely to perish from cardiovascular disease and nearly four times more likely to die of cancer [17]. The vast majority (93\%) of premature deaths in our study were associated with these three lifestyle choicessmoking, obesity and alcohol consumption- at a financial cost of $\$ 86.3$, $\$ 77.1$, and $\$ 26.3$ billion, respectively. A reduction in these three PDLD could generate an annual savings in monetary costs of $\$ 190$ billion annually. The recent study by Kvaavick et al., indicated that individuals who smoke, do not exercise, eat poorly, and drink alcohol had an overall mortality risk equivalent to being 12 years older vis-à-vis people who do not engage in these lifestyle behaviors [17].

Our study has two notable limitations. First, lifestyle choices may also be affected by other determinants adversely affecting health such as emotional distress and financial difficulties. We also made the assumption that individuals who perish in a given age group from PDLD would have avoided the PDLD; he/she would have the same probability of dying within that age group as any other individual.

Our study shows smoking as the most prevalent and expensive lifestyle choice culminating in premature mortality, but notably, to a lesser degree than in the previous decade. In our opinion, this reduction in PDLD reinforces the imperative to continue to promote a policy of modest, but achievable lifestyle behavior alterations on an individual level while also implementing strategic initiatives at a population level. For example, Asaria et al., showed that implementing four key elements of the WHO Framework Convention on Tobacco Control coupled with diminishing salt intake by $15 \%$ over a ten year duration among 23 countries could avoid 13.8 million chronic disease deaths at a minimal financial cost $[18,19]$. The WHO Tobacco Control strategies were designed to reduce demand for tobacco through measures such as price and tax measures, non-price measures, education and awareness, and regulation. Additional strategies were employed to reduce the supply of tobacco. These included measures such as diminishing illicit trade in tobacco products, limiting sales to minors and support for economically viable alternative activities. In much the same way, on an individual level, persons who smoke need to understand the adverse impacts of such a lifestyle choice because a decision to smoke imposes a monetary cost of lost productivity and adverse health outcomes which may culminate in premature mortality.

\section{References}

1. Molinari NAM (2004) The effect of health care on population health. The Lancet 364: 1558-1560.

2. Schneyer S, Landefeld JS, Sandifer FH (1981) Biomedical research and illness: 1900-1979. Milbank Mem Fund Q Health Soc 59: 44-58.

3. Vehorn CL, Landefeld JS, Wagner DP (1982) Measuring the contribution of biomedical research to the production of health. Res Pol 11: 3-13.

4. Wolfe BL (1986) Health status and medical expenditures: is there a link? Socia Science Medicine 22: 993-999.

5. Keeney R (2008) Personal Decisions are the Leading Cause of Death Operations Research 56: 1335-1347.

6. Centers for Disease Control and Prevention (2002a) Deaths: Final data for 2000. National Vital Statistics Rep 50

7. http://www.cdc.gov/nchs/fastats/deaths.htm

8. Centers for Disease Control and Prevention (2002b) Annual smokingattributable mortality, years of potential life lost, and economic costs-US 19951999. MMWR Weekly 15: 300-303.

9. http://www.census.gov/compendia/statab/cats/births_deaths_marriages_ divorces.html

10. Allison DB, Fontaine KR, Manson JE, Stevens J, Vanltallie TB (1999) Annual deaths attributable to obesity in the US. JAMA 282: 1530-1538.

11. Siedel JC (1999) The burden of obesity and its sequelae. Disease Management Health Outcomes 1: 13-21.

12. Bell CG, Walley AJ, Froguel P (2005) The genetics of human obesity. Nat Rev Genet 6: 221-234.

13. Balia S, Jones AM (2008) Mortality, lifestyle and socio-economic status. Journal of Health Economics 27: 1-26.

14. McGinnis JM, Foege WH (1993) Actual causes of death in the US. Journal of the American Medical Association 270: 2207-2212.

15. Mokdad AH, Marks JS, Stroup DF, Gerberding JL (2004) Actual causes of death in the US, 2000. JAMA 291: 1238-1245.

16. Hartman M, Martin AB, Benson J, Catlin A (2013) National Health Spending in 2011: Overall growth remains low, but some payers and services show signs of acceleration. Health Aff 32: 17-199.

17. Kvaavik E, Batty GD, Ursin G, Huxley R, Gale CR (2010) Influence of individual and combined health behaviors on total and cause-specific mortality in men and women: The United Kingdom health and lifestyle survey. Archives in Internal Medicine 170: 711-718.

18. Asaria P, Chisholm D, Mathers C, Ezzati M, Beaglehole R (2007) Chronic disease prevention: health effects and financial costs of strategies to reduce salt intake and control tobacco use. Lancet 370: 2044-2053.

19. http://www.who.int/fctc/WHO_FCTC_summary_January2015.pdf?ua=1 